\title{
Concrete Capillarity under Different Curing Conditions Produced in Kurdistan-Iraq
}

\author{
Bengin A. Herki ${ }^{1,2}$ \\ 1 Bayan University, Erbil, Kurdistan, Iraq \\ 2 Soran University, Soran, Erbil, Kurdistan, Iraq \\ * e-mail: bengin2004@yahoo.co.uk
}

\begin{abstract}
This study discussed the effect of the curing condition on the capillary water absorption of concrete incorporating the locally available materials. The compressive strength and ultrasonic pulse velocity (UPV) as part of mechanical and durability properties of concrete were also investigated. The engineering properties were conducted on concrete under three different curing conditions at different curing ages of 2 days, 7 days and 28 days. The three different curing conditions were water curing, dry curing and gunny-covered curing. According to the results obtained, the concrete under water curing condition demonstrated a lower capillary water absorption (CWA) at 2 and 7 days ages and the concrete under gunny-covered condition demonstrated lower CWA at 28 days of age, compared with the other curing conditions. It is interesting to see that the compressive strength ( $38 \mathrm{MPa}$ ) of concrete was almost the same at 28 days age under the gunny-covered and water curing conditions.
\end{abstract}

Keyword: Capillary Water Absorption; Concrete; Strength; UPV

\section{INTRODUCTION}

Concrete as the most popular artificial material on Earth has been used to build civilizations thousands of years ago. Concrete, as a composite material, is one of the most used and known material in the world and nowadays thousands of tons of concrete are being used at different parts around the globe. It has lots of advantages; however, like any other material, it also has some disadvantages and limitations (Neville 2011). Curing is the name given to the procedures used for promoting the hydration process of cement, and consists of a control of temperature and the moisture movement from and into the concrete (Neville 2011). Curing may take place after the fresh concrete is being placed in the site, because the hydration of concrete takes time, it usually takes days, so curing must be done for a reasonable period of time in order for concrete to achieve its initial strength and durability. However, many factors - other than the curing process - also affect the development of the mechanical and durability properties of concrete. These factors include the quality and quantity of cement used in the mix, grading of aggregates, maximum nominal size, shape and surface texture of aggregate, as well as water/cement ratios, degree of compaction, and the presence or otherwise of clayey particles and organic materials in the mix (Ogah 2016). In the study conducted by James, et al., (2011) it was reported that for the concretes that are subjected to extreme ambient, the most important factor for the concrete in order to gain the design strength and the ultimate strength is a proper curing after placing and at the early stage of hardening, meaning that the curing process is managed by the rate of hydration and the level of moist loose in the concrete.

There are various types of curing and of course, the adoption of the particular condition depends on the environment and on the nature of work. There are six different types of curing which are generally adopted around the globe, including shading 
of concrete network, covering concrete with gunny bags, sprinkling of water, ponding method, membrane curing and steam curing. In the study conducted by James et al. (2011) a summary of the effect of the curing method on the compressive strength with curing age for all the curing methods of ponding, wet covering, sprinkling, plastic sheeting, and uncured type in the open air and the cubes left uncured for two days prior to curing were shown. It was noticed that there was a significant increase in the concrete strength with the curing age depending on the curing method adopted. It was clearly shown the ponding curing gave the highest compressive strength compared with other curing methods at the same curing age, because it is working on the improving the pore system of the concrete and lowering the permeability of the concrete which obviously results in a greater degree of cement hydration and lowering in the rate of moisture lose from the concrete cubes. In turn, the specimens with totally uncured method gave the lowest compressive strength. Because the concrete was not cured, the hydration process was not completely done therefore, the concrete specimens did not achieve their maximum strength. Since the specimen left totally uncured gave the lowest result, this suggests that curing is very important and necessary for all concrete structures especially in hot environments, for example in very hot weather during summer and in very cold weather during the winter conditions in Kurdistan Region-Iraq.

In an experimental study conducted by Gayarre (2013) the ordinary concretes density value of two samples each, under different curing condition, was reported. It showed that the sample which has been cured under the open air conditions gives a lower value than the one which is cured under the controlled conditions. It also reported the effect of both types of curing on the compressive strength of concrete although the compressive strength value of both samples were nearly the same in the first 7-days but at the age of 28-days, the specimen which was cured in a controlled environment showed a higher compressive strength in the same period of curing than the one which was cured outdoors. Similar results were reported by Safiuddin (2007) and Ibrahim (2013).

In a recently published study conducted by Maslehuddin (2013) the effect of the curing methods on the shrinkage and corrosion resistance of concrete was reported. The concrete samples were put under different curing conditions and were cured either by water ponding, covering with wet burlap, or by the application of the curing compound. It was noticed that the maximum plastic shrinkage strain was noticed in those samples which were cured by covering them with a plastic sheet.

The effect of temperature on the capillary water absorption in different building materials at three different levels of temperature at (20,25 and $30{ }^{\circ} \mathrm{C}$ ) was investigated by Karagiannis (2016). The study showed that there is a linear relation between the capillary water rise and temperature for all building materials such as (brick, stones and hydraulic mortars). Although there was a difference in the linearity slope for each material but they observed that rate of capillary water absorption increases along with the temperature .

\section{EXPERIMENTAL METHODOLOGY}

\section{Materials}

This study experimentally investigated the effect of different curing methods and ages on the capillary water absorption (CWA) of the concrete incorporating the locally available materials produced in the Kurdistan region of Iraq. Ordinary Portland cement: CEM I/ 42.5 R (According to EN 197-1:2011) manufactured by Urmia cement company imported from Iran. This cement was used in the study for both batches. The characteristics of the ordinary Portland cement are shown in Table 1. For this investigation, the locally

Table 1. Characteristics of Portland cement

\begin{tabular}{|c|c|c|c|}
\hline Constitute & OPC (wt. \%) & Constitute & OPC (wt. \%) \\
\hline Lime $(\mathrm{CaO})$ & 64.64 & $(\mathrm{C} 3 \mathrm{~S})$ & 21.45 \\
\hline Silica $\left(\mathrm{SiO}_{2}\right)$ & 21.28 & $(\mathrm{C} 2 \mathrm{~S})$ & 9.16 \\
\hline Alumina $\left(\mathrm{Al}_{2} \mathrm{O}_{3}\right)$ & 5.6 & $(\mathrm{C} 3 \mathrm{~A})$ & 10.2 \\
\hline Iron Oxide $\left(\mathrm{Fe}_{2} \mathrm{O}_{3}\right)$ & 3.36 & Loss on ignition & 0.64 \\
\hline Magnesia $(\mathrm{MgO})$ & 2.06 & Lime saturation factor & 0.92 \\
\hline Sulphur Trioxide $\left(\mathrm{SO}_{3}\right)$ & 2.14 & & \\
\hline Nitrous Oxide $\left(\mathrm{N}_{2} \mathrm{O}\right)$ & 0.0 & & \\
\hline
\end{tabular}


Table 2. Particle size distribution of fine aggregate

\begin{tabular}{|c|c|c|c|c|}
\hline $\begin{array}{c}\text { Sieve size } \\
(\mathrm{mm})\end{array}$ & $\begin{array}{c}\text { Weight retained on } \\
\text { each sieve }(\mathrm{g})\end{array}$ & $\begin{array}{c}\text { Weight retained on each } \\
\text { sieve (\%) }\end{array}$ & Cumulative sieve (\%) & $\begin{array}{c}\text { Cumulative sieve weight } \\
\text { passing (\%) }\end{array}$ \\
\hline 4.75 & 143 & 14.3 & 14.3 & 85.7 \\
\hline 2 & 302 & 30.2 & 44.5 & 55.5 \\
\hline 1 & 166 & 16.6 & 61.1 & 38.9 \\
\hline 500 mic & 292 & 29.2 & 90.3 & 9.7 \\
\hline 250 mic & 86 & 8.6 & 98.9 & 1.1 \\
\hline Pan & 11 & 1.1 & 100 & 0 \\
\hline
\end{tabular}

available river sand in Soran town, Erbil, Kurdistan, Iraq was used. The grading size distribution is shown in the Table 2.

Natural coarse aggregate with max size of $12.5 \mathrm{~mm}$ was also used in the concrete mixes. The physical property of the coarse aggregate were tested in a laboratory including specific gravity and water absorption according to the ASTM standard, the results are shown in Table 3. The grading size distribution is shown in the Table 4.

For this experiment, ordinary water was used for mixing and curing of the cubes. The water used was drinkable and pure. It was free from any impurities which may have a negative effect on the hydration of cement and other mechanical properties of concrete.

\section{Mix proportion}

The mix proportion used for the present experimental study was $(1: 2.5: 3.5)$ more specifically (1) cement, (2.5) fine aggregate and (3.5) coarse aggregate. The mix was prepared according to the absolute volume mix design method. The required amount of each material to prepare the concrete mix was calculated based on the standards. The amount of required materials is shown in the below; $10 \%$ of the total weight of the mix was added to work as a backup for the materials that are being loosened during the mixing process. The water to cement ratio (W/C) used for was 0.5 and kept constant for all mixes. For ease of demoulding, before filling the cubes with concrete, the interior side of all moulds were oiled. The casting of the cubes were put in three layers; each layer was compacted 25 times by using a rod and the outer side of the cube was hammered by a plastic hummer to free the cube from air bubbles. In total, 27 cubes were prepared and 9 of them were divided in half by using a metal sheet to be used for CWA test. The cubes were covered by plastic sheets and kept at a room temperature for $24 \mathrm{~h}$, after the period of $24 \mathrm{~h}$ the cubes were ready to be demoulded. The cubes were demoulded using a water pump pressure as shown in Figure 1. Afterwards, the cubes were dived into three groups based on their curing method, group one was placed in the water tank, group two was covered with a gunny bag and the last group was placed in outside environment till the day of the test at different curing times of 2, 7, 28 ages.

Table 3. Physical properties of natural coarse aggregate

\begin{tabular}{|l|c|}
\hline \multicolumn{1}{|c|}{ Property } & NCA \\
\hline Bulk Specific Gravity(OD) & 2.61 \\
\hline Water Absorption \% & 0.53 \\
\hline Particle Shape/Texture & Sub angular/Partially rough \\
\hline Types & Crushed \\
\hline color & Grey \\
\hline
\end{tabular}

\section{TESTING METHODS}

\section{Slump test}

The slump test assesses the consistency of fresh concrete. It is used in order to check whether the used amount of water which was added to the mix is correct or not. It is used to determine

Table 4. Particle size distribution of natural coarse aggregate

\begin{tabular}{|c|c|c|c|c|}
\hline Sieve size, $\mathrm{mm}$ & $\begin{array}{c}\text { Weight retained on } \\
\text { each sieve }(\mathrm{g})\end{array}$ & $\begin{array}{c}\text { Weight retained on } \\
\text { each sieve (\%) }\end{array}$ & Cumulative sieve (\%) & $\begin{array}{c}\text { Cumulative sieve } \\
\text { weight passing (\%) }\end{array}$ \\
\hline 12.5 & 675 & 67.50 & 67.50 & 32.50 \\
\hline 9.5 & 238 & 23.80 & 91.30 & 8.7 \\
\hline Pan & 87 & 8.7 & 100 & 0 \\
\hline
\end{tabular}




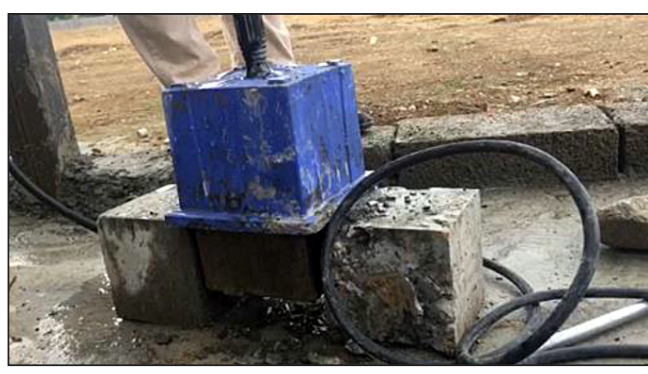

Fig. 1. Water pressure pump

the workability of fresh concrete and it is being measured right after the concrete is being mixed. This test was carried out according to the BS EN 12350-2, Testing fresh concrete.

\section{Compressive Strength}

For this test, a set of six concrete cube of $150 \times 150 \times 150 \mathrm{~mm}$ were tested for curing ages of 2, 7 and 28 days; two cubes were used for each curing method, i.e. water curing, dry curing and gunny-covered curing. Each cube was put in its curing condition till the day of the test, and the test was performed according to the standards. The test was carried out in a standard compression machine with the capacity of $2000 \mathrm{KN}$, the load was applied at a rate of $0.5 \mathrm{MPa} / \mathrm{s}$ (Fig. 2).

\section{Ultrasonic Pulse Velocity}

Ultrasonic measurements are used in structural engineering to determine the material properties, detect defects and assess deterioration (Yaman, 2001). Ultrasonic pulse velocity (UPV) is a long-established, non-destructive test method which determines the velocity of longitudinal (compressional) waves (Neville, 2011). A UPV test in concrete is performed in order to determine the uniformity of concrete, cavities, cracks and defects, as well as the presence of voids,

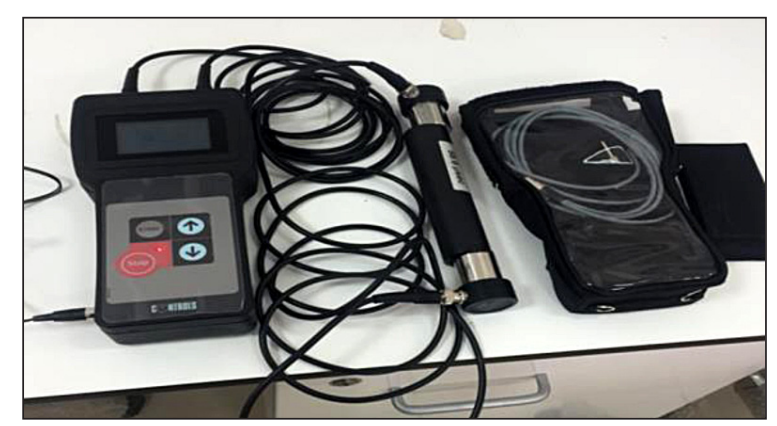

Fig. 3. UPV Instrument

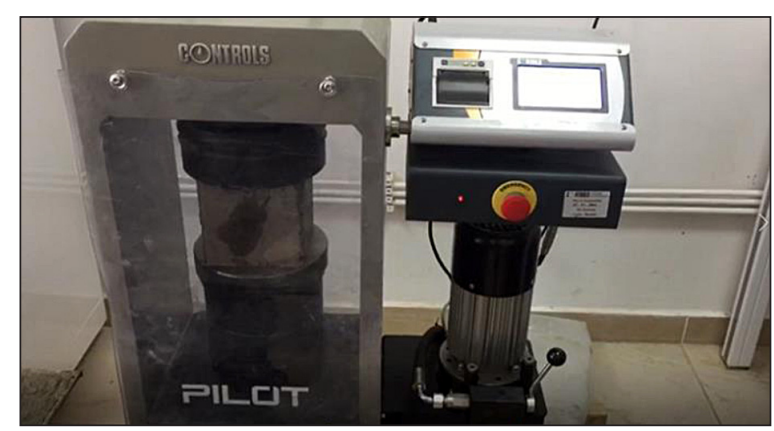

Fig. 2. Compression Machine

honeycomb and discontinuities. This test was carried out at different ages of concrete curing according to BS EN 12504-4:2004. While performing this test, the direct transmission method was used to measure the velocity, using a portable ultrasonic non-destructive digital indicating tester on $150 \times 150 \times 150 \mathrm{~mm}$ cube specimens as shown in Figure 3. The equipment consisted of two metallic transducers: one for transmitting the velocity and the other one for receiving the pulse.

\section{Capillary Water Absorption}

After the mix was prepared, the moulds of $150 \times 150 \times 150 \mathrm{~mm}$ size were used and divided in half by using a piece of steel sheet, as shown in Figure 4. The mix was cast and the cubes were demoulded after $24 \mathrm{~h}$ of casting; then, for each curing age 2 days, 7 days and 28 days six cubes were prepared - two for each curing condition. The specimens of $150 \times 150 \times 75 \mathrm{~mm}$ size were used for the CWA test. These specimens were cured under different conditions until testing. Saturated Surface Dry (SSD) specimens were kept in a hot air oven at $100^{\circ} \mathrm{C}$, until a constant weight was attained. For the CWA test, the absorption of water by the concrete specimens was determined by measuring the increase in the mass resulting from water absorption as a function of time when only one surface of the specimen is exposed to water on a support device (Herki et al., 2013). The schematic diagram of the CWA (moisture migration) test setup used is shown in Figure 4. During the test period, the weight gain was monitored at intervals of $1,3,5,7,10,20,30,45,60,120,180$, 1440 and 2880 minutes. The water level was kept constant throughout the test. The CWA values are the average of two test samples. The weight $(\mathrm{g})$ of water absorbed per unit area $\left(\mathrm{mm}^{2}\right)$ was plotted against the square root of time (minute). The units are in $\mathrm{g} / \mathrm{mm}^{2} \min ^{1} / 2$. Water curing involved 
placing the cubes in the water tank, dry curing consisted in placing the cubes in the open space where it is in contact with the outdoor weather and away from the rain or from any water curing, the gunny bag curing involved covering the cubes with gunny bag and curing the cubes by spraying water on the covered gunny 3 times daily. After each curing period, the cubes were placed in the oven for 48 hours, as shown in fig at a temperature of $105+-5{ }^{\circ} \mathrm{C}$ until it reached the condition were the weight loss percentage is less than 0.01 percentage. The cubes which were in the oven were weighted 4 times daily. When the drying process was over, each sample was covered with a plastic bag so there was no more moisture loss and they were prepared for the capillary water absorption test. A metallic tray was filled with water and a support was placed in the tray so the cubes could rest on it, the level of water was just in touch with a surface of the cube after the samples were rested on the support weighting process starts, according to the time table specified, it starts from $1 \mathrm{~min}$ and ends after 48 hours for each specified time weight of cubes were recorded. This process was repeated after 7 days of curing and after 28 days of curing. After the test was started, water was added to the tray to ensure that the surface of the cubes was in touch with the water. The rise of water from the capillaries of concrete was obvious and clearly seen as it is being shown in Figures 4 and 5.

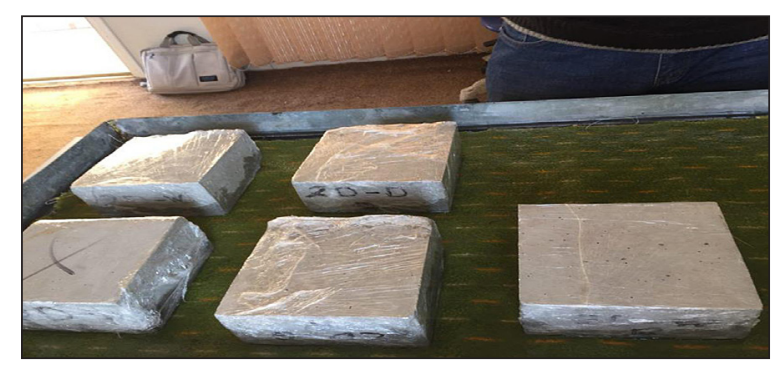

Fig. 4. CWA test setup

\section{RESULTS AND DISCUSSION}

\section{Compressive Strength}

The compressive strength of the concrete samples at the age of 2, 7, 28 days for different curing conditions is shown in Figure 6. The results mentioned in the table below showed that after taking the average of two concrete samples for each curing condition. The compressive strength of the sample after 2 days of curing is relatively the same for all curing conditions and the value ranged between 12.50 and $12.73 \mathrm{MPa}$. The reasons why the results are the same, is due to the incompleteness of the hydration process and it is clear that the cubes are at the first stage of the hydration process. However, the development of the compressive strength of the cubes after 7 days of curing indicates -a slight difference between the concrete samples for different curing conditions. Because the hydration process has developed more compared with the hydration process after 2 days of curing, the compressive strength ranged from 20.92 to $22.39 \mathrm{MPa}$. Finally, the investigated samples reached the maximum compressive strength after 28 days, ranging from 30.71 to $37.86 \mathrm{MPa}$. The reason of this clear difference between the different types of curing stems from the fact that the hydration process reached its final stages and there is a little or no cement remaining to be hydrated by water. As a result of this study, it was found that

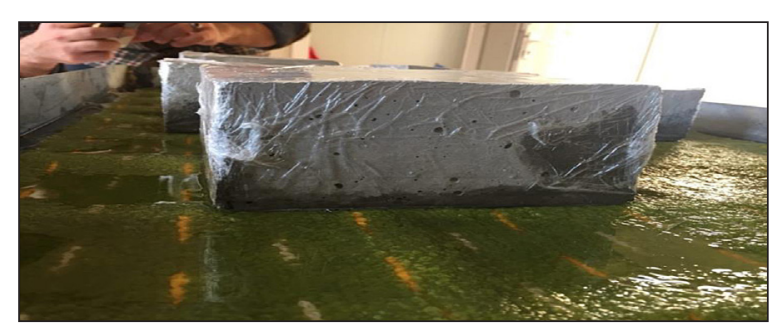

Fig. 5. Specimen water uptake

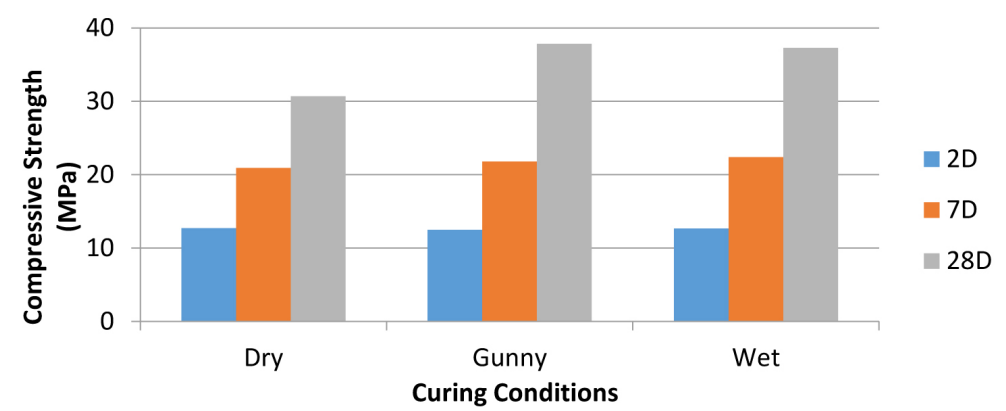

Fig. 6. Compressive strength of concrete under different curing conditions and times 
by increasing the curing age, the compressive strength increases as well, which means they are directly proportional to curing time. The same results were reported by James et al. (2011). The most effective curing condition mentioned above is covering the cube by using the gunny bag cause it has given the highest compressive strength, unlike the result that was obtained by Safiuddin et al. (2007) who found that wet curing was the best curing condition when it comes to gaining strength, our fault might be due to the improper drying process of cubes because the oven size was very small and the drying period was not the same for every cube. Wet curing is also a good way for obtaining a satisfactory result because there is a very slight difference between the strength developed in the cubes that have been cured with gunny bag and wet curing condition; however, the dry curing is not very desirable when it comes to the development of the compressive strength in the concrete samples, as Ibrahim et al. (2013) mentioned in their research.

\section{Ultrasonic Pulse Velocity}

The time taken by the wave to travel from one side of concrete to the opposite side of the sample is being indicated by the porosity of the concrete; hence, ultrasonic pulse velocity (UPV) depends largely on the pore system and the density of concrete. The Figure 7 shows the result of the UPV test at different curing ages for three different curing conditions. As in the previous test, the results were taken as an average of the test on two cubes. It is clear that as the age of curing increases for different curing conditions the hydration process develops more, which means that the cavities and pores in the concrete decreases. Hence, the results of UPV test increase along with the curing age. This study shows that wet curing is the best between the three conditions mentioned above when it comes to the UPV test. Similar results were reported by Ghosh (2018), Pierre (2016), Mohammed Rahman (2016), Aziz Hasan (2016) and Safiuddin et al. (2007).

Figure 8 shows the correlation between compressive strength and UPV of concrete under different curing conditions and different curing times similar to what Aziz Hasan, et al., (2016) reported, the correlation is described by a function as shown below.

$$
\mathrm{Y}=55.587 \mathrm{X}-187.15 \mathrm{R}^{2}=0.9105
$$

This equation shows a strong correlation $\left(\mathrm{R}^{2}=0.9105\right)$ where $\mathrm{X}$ representing UPV $(\mathrm{km} / \mathrm{s})$ and $\mathrm{Y}$ is the compressive strength (MPa).

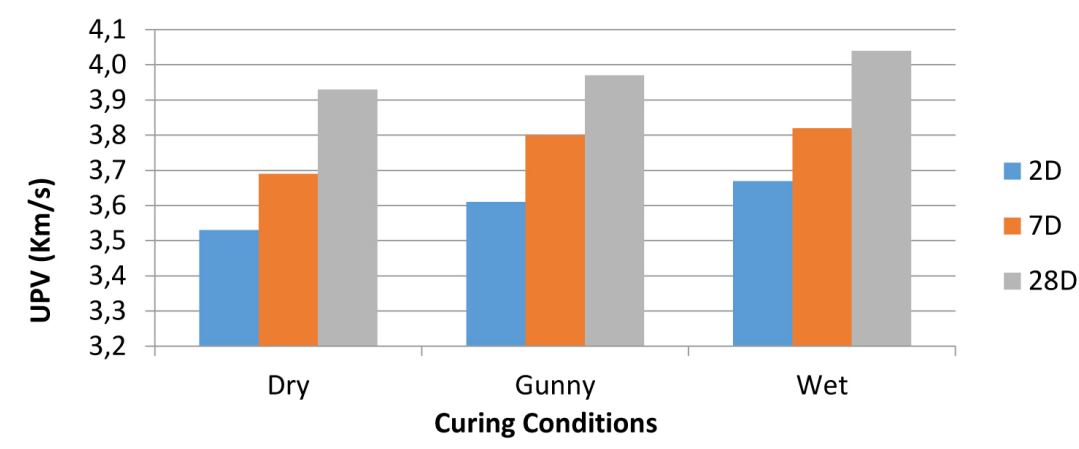

Fig. 7. UPV of concrete under different curing conditions

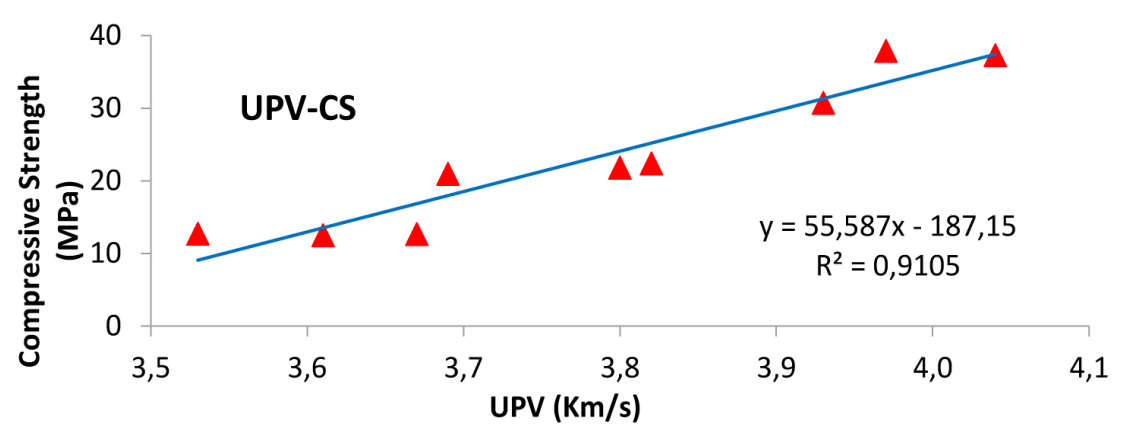

Fig. 8. Correlation between strength and UPV 


\section{Capillary Water Absorption}

The capillary water absorption (CWA) of the concrete under different curing times and three different curing conditions is being shown in the Figures 9-11. CWA is defined as the rate of water absorption per unit area and expresses the tendency of the concrete to transmit the water through capillarity. The results are the average of two cubes for each age and each curing condition.

\section{CWA-2Days}

After two days of curing, the cubes were cured under dry conditions as it is shown in the Figure 9. At the early stage of the test, there is a very sharp increase in the water absorption from the $1^{\text {st }}$ min until 24 hours and from the 24 hours of the test till 48 hours there is a very slight increase in the absorption of water. The total weight of water which was absorbed by the cubes from the beginning of the test till the end of it was (229.5g), CWA for wet and gunny bag curing of cubes from beginning of the test till 24 hours the water absorption of the cubes is very fast and noticeable; after that period, the absorption rate decreases automatically and there is a slight increase in the water absorption. As shown in the figure below, the total weight of water absorbed by the cubes for wet curing was $(189.5 \mathrm{~g})$ and for the cubes which were covered in gunny bag (205g) (Yazicioglu, 2010).

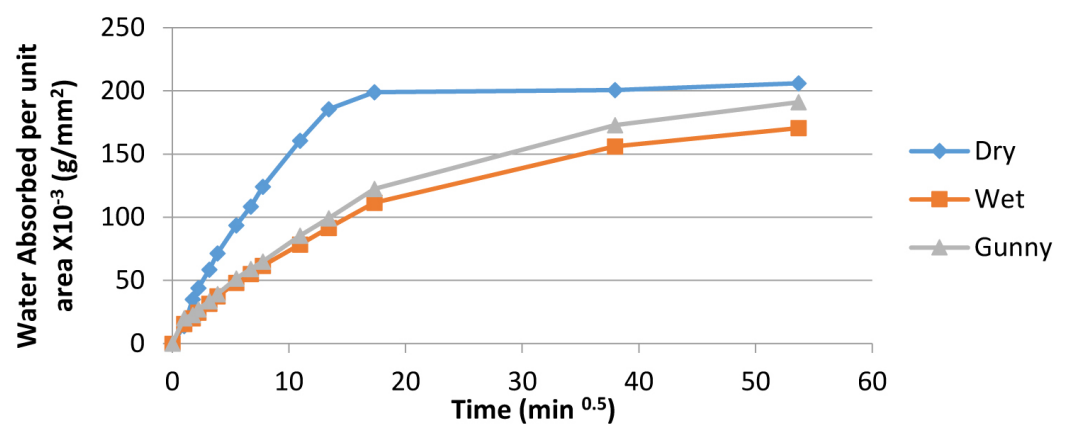

Fig. 9. CWA of concrete under different curing conditions -2 days of age

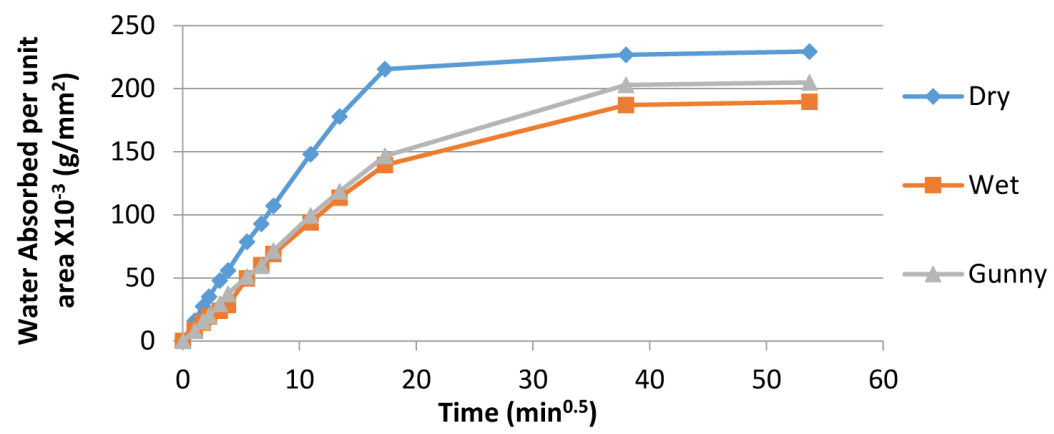

Fig. 10. CWA of concrete under different curing conditions-7 days age

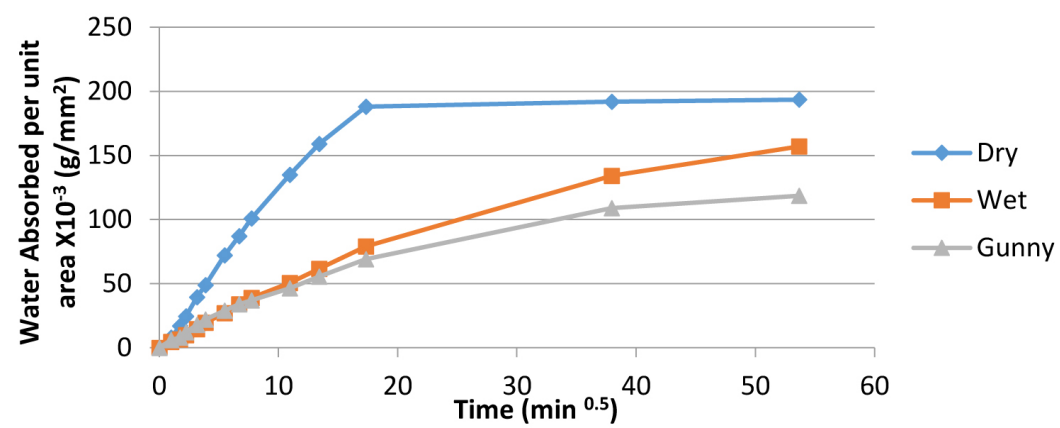

Fig. 11. CWA of concrete under different curing conditions-28 days age 


\section{CWA-7Days}

After 7 days of curing again, a CWA test was run on the cubes by following the same process of 2 days after curing. For the 7 days old dry conditioned cubes, as it is shown in Figure 10, there is a sharp increase in the absorbed water from the start point of the test to the $5^{\text {th }}$ hours and it can be seen clearly that afterwards the increasing rate is very low till the 48 hours of the test period; the total weight gained by the dry cubes was $(206 \mathrm{~g})$. For the gunny bag and wet cured cubes the water absorption is increasing with a moderate rate till the $5^{\text {th }}$ hour of the test, as shown in figure below. Afterwards, there is an increase in the absorption rate till the end of the test, the water absorbed by the wet and gunny bag cured cubes reached $(170.5 \mathrm{~g})$ and $(191 \mathrm{~g})$, respectively. Similar results were reported by N. Karagiannis (2016), Basheer (2001) and Javier Castro (2011).

\section{CWA-28Days}

For the samples following 28 days of curing, the CWA test was performed, the capillary absorption for 28 days dry cured cubes, as shown in the Figure 11 below, from the start of the test to the $5^{\text {th }}$ hour there is a rapid rise of the water absorbed by the cubes. Then, from the $5^{\text {th }}$ hour to the $48^{\text {th }}$ hour of the test the rate of absorption slows down sharply and there is slight increase in the total water absorbed by the cube (193.5g). For both the gunny bag and wet cured condition, as it is shown in the Figure 11, there is a very slow increase in the rate of water absorption till the $5^{\text {th }}$ hour of the test, and after that the rate of water absorption increases significantly till the end of the test. The water absorbed by cubes for both cured condition is as follows: $(157 \mathrm{~g})$ was absorbed by the wet cured cubes and $(118.5 \mathrm{~g})$ was absorbed by the gunny bag cured cubes.

By analysing the taken data from the CWA test it is clear that for all curing ages, the dry cured cubes have the highest absorption compared to other conditions and it can be concluded that as the curing age increases for all cubes and for every curing conditions, the CWA of the concrete decreases. The reason is that as the curing ages increases, the hydration process develops more and leads to minimizing in the pore system as well as reduction in the capillary pore size. Thus, the amount of water absorbed through capillarity deceases when the curing age increases, also when the relative humidity increases the sorptivity of the cubes decreases, similarly to the results obtained by Castro et al. (2011). It was also determined that the CWA of the concrete increases along with the temperature increases,. Similar results were reported by N. Karagiannis et al. (2016).

\section{CONCLUSION}

The capillary water absorption (CWA), as indicated by the rate of water absorbed per unit area decreases when the curing time increases, as expected; this is accompanied by an increase in the compressive strength and UPV. It is interesting to see that the concrete under the wet curing condition demonstrated a lower CWA at 2 and 7 days ages and the concrete under gunny covered condition demonstrated lower CWA at 28 days age compared with the other curing conditions. Due to the incompleteness of the hydration process, the concrete engineering properties under different curing conditions at early ages were almost the same. It is interesting to see that the compressive strength of concrete was almost the same at 28 days age under wet and gunny covered curing conditions. The dry curing condition demonstrated a lower compressive strength and UPV, as well as higher CWA than the other two curing conditions, as expected. However, the UPV values were higher under the wet curing conditions than under the other two.

\section{REFERENCES}

1. Abyaneh, H.S. Wong, and Buenfeld N.R. 2014. Computational investigation of capillary absorption in concrete using a three-dimensional mesoscale approach, Computational Materials Science 87, 54-64.

2. ACI. 308, 2016. Guide to External Curing of Concrete. American Concrete Institute, ACI 308R-16, $1-6$.

3. Ahmed, M.R. 2015. Assessment of Compressive Strength of Concrete Based On Combination of Different Sizes of Aggregate. International Journal of International Journal of Advanced Structures and Geotechnical Engineering, 04, 148-152.

4. Bozkurt, N. and Yazicioglu, S. 2010. Strength and capillary water absorption of lightweight concrete under different curing conditions, Indian Journal of Engineering and Materials Sciences, 17, pp. 145-151. 
5. Brunetaud, X, Linder, R, Divet, L, Duragrin, D, and Damidot, D. 2007. Effect of curing conditions and concrete mix design on the expansion generated by delayed ettringite formation, Materials and Structures.

6. Castro, J., Bents, D. and Weiss, J. 2011. Effect of sample conditioning on the water absorption of concrete, Cement and Concrete Composites, Elsevier Ltd, 33, 805-813.

7. Chen, D., Yu, X.-T., Shen, J., Liao, Y.-D. \& Zhang, Y. 2017. Investigation of the curing time on the mechanical behavior of normal concrete under triaxial compression. Construction and Building Materials, 147, 488-496.

8. Ferreira, L., de Brito, J. and Saikia, N. 2012. Influence of curing conditions on the mechanical performance of concrete containing recycled plastic aggregate, Construction and Building Materials, 36, 196-204.

9. Ghosh, R., Sagar, S.P., Kumar, A., Gupta, S.K. and Kumar, S. 2018. Estimation of geo-polymer concrete strength from ultrasonic pulse velocity (UPV) using high power pulsar. Journal of Building Engineering, 16, 39-44.

10. Ibrahim, M., Shameem, M., Al-Mehthel, M. and Maslehuddin, M. 2013. Effect of curing methods on strength and durability of concrete under hot weather conditions. Cement and Concrete Composites, 41, 60-69.

11. James, A.M., Gadzama E.W., Anametemok V. 2011. Effect of curing methods on the compressive strength of concrete. Nigerian Journal of Technology, 30 .

12. Karagiannis, N., Karoglou, M., Bakolas, A. and Moropoulou, A. 2016. Effect of temperature on water capillary rise coefficient of building materials. Building and Environment, 106, 402-408.

13. Khatib, J.M. and Clay, R.M. 2004. Absorption characteristics of metakaolin concrete, Cement and Concrete Research, 34(1), 19-29.

14. Khatib, J.M., Herki, B.A. and Kenai, S. 2013. Capillarity of concrete incorporating waste foundry sand, Construction and Building Materials, Elsevier Ltd, 47, 867-871.

15. Khatib, J. M. and Mangat, P.S. 1995. Absorption characteristics of concrete as a function of location relative to casting position $\mathrm{j}$, Cement and Concrete Research, 25(5), 999-1010.
16. Gayarre L.F., López-Colina Pérez, C., Serrano López, M.A. and Domingo Cabo, A. 2014. The effect of curing conditions on the compressive strength of recycled aggregate concrete. Construction and Building Materials, 53, 260-266.

17. Basheer L., Kropp J., Cleland D.J. 2001. Assessment of the durability of concrete from its permeation properties: a review. Construction and Building Materials 15, 93-103.

18. Mohammed, T.U. and Mahmood, A.H. 2016. Effects of maximum aggregate size on UPV of brick aggregate concrete. Ultrasonic, 69, 129-36.

19. Mohammed, T.U. and Rahman, M.N. 2016. Effect of types of aggregate and sand-to-aggregate volume ratio on UPV in concrete. Construction and Building Materials, 125, 832-841.

20. Naderi1, R.S. and Shayanfar M.A. 2009. Comparison of different curing effects on concrete strength. 3rd International Conference on Concrete \& Development, 507-516.

21. Nahata, Y., Kholia, N. and Tank, T.G. 2014. Effect of Curing Methods on Efficiency of Curing of Cement Mortar. APCBEE Procedia, 9, 222-229.

22. Neville A.M., and Brooks J.J. 2004. Concrete Technology, Longman scientific and technical, New York, USA.

23. Neville, A.M. 2011. Properties of Concrete, fourth edition, Pearson educated limited, Essex, UK.

24. Ogah, O. 2016. Effect of Curing Methods on the Compressive Strength of Concrete. International Journal of Engineering and Computer Science.

25. Safiuddin, S.N.R.A.M.F.M.Z. 2017. Effect of Different Curing Methods on the Properties of Microsilica Concrete. Australian Journal of Basic and Applied Sciences 1(2), 87-95.

26. Saint-Pierre, F., Philibert, A., Giroux, B. and Rivard, P. 2016. Concrete Quality Designation based on Ultrasonic Pulse Velocity. Construction and Building Materials, 125, 1022-1027.

27. Shi, C., Wang, D., He, F. and Liu, M. 2012. Weathering properties of $\mathrm{CO} 2$-cured concrete blocks, Resources, Conservation and Recycling, Elsevier B.V., 65, 11-17.

28. Yaut, C.H.M.H.R. 1987. Water Movement in Porous Building Materials--IX. The Water Absorption and Sorptivity of Concretes. Building and Environment, 22, 77-82. 